Supporting Information

\title{
Electronic and Geometric Effects on Chemical Reactivity of 3d-Transition-Metal-Doped Silver Cluster Cations toward Oxygen Molecules
}

Shun Sarugaku, Masashi Arakawa*, Tomoki Kawano, and Akira Terasaki*

Department of Chemistry, Faculty of Science, Kyushu University,

744 Motooka, Nishi-ku, Fukuoka 819-0395, Japan 
(a) $\mathrm{AgN}_{\mathrm{N}-1} \mathrm{Sc}^{+}$

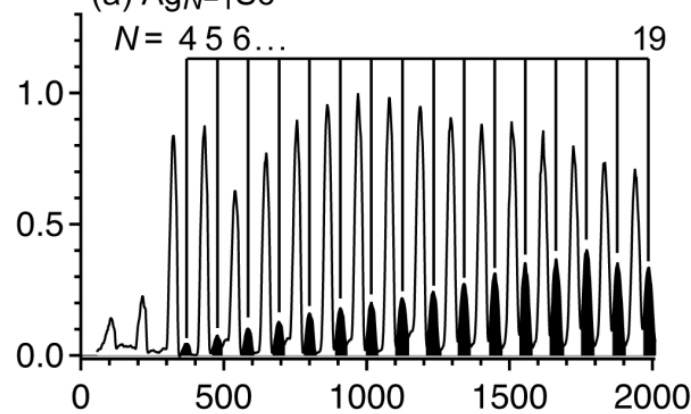

(b) $\mathrm{AgN}_{\mathrm{N}-1} \mathrm{Ti}^{+}$
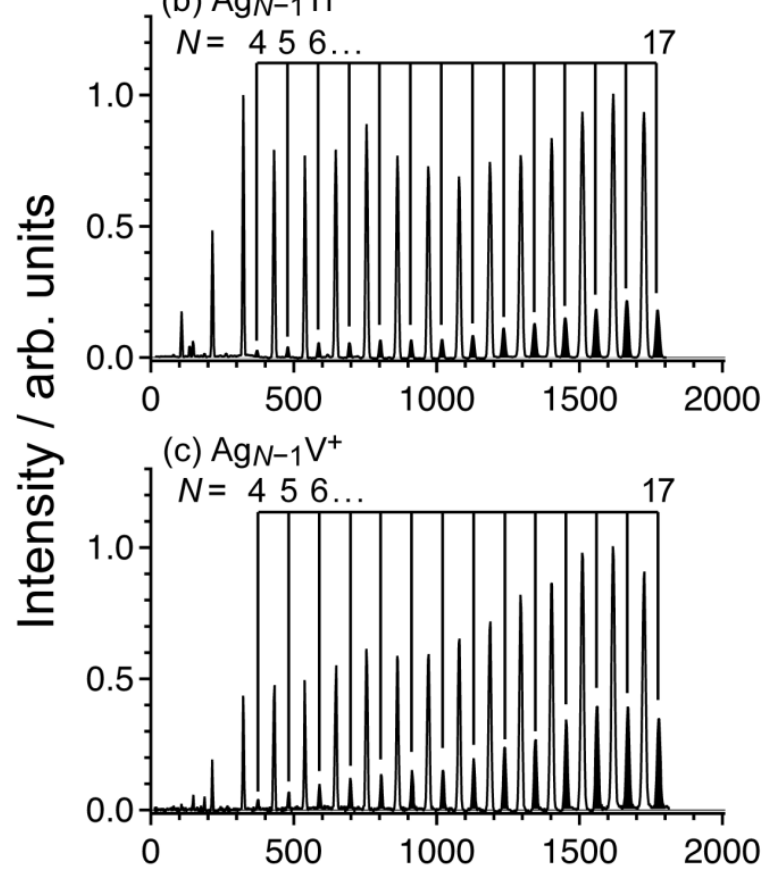

(d) $\mathrm{Ag}_{N-1} \mathrm{Cr}^{+}$

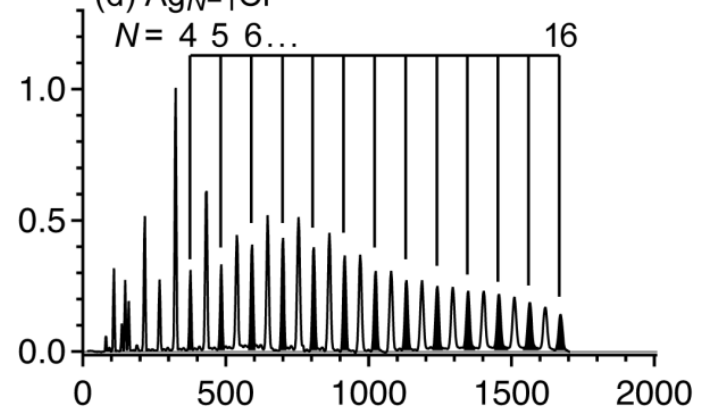

(e) $\mathrm{Ag}_{\mathrm{N}-1} \mathrm{Mn}^{+}$
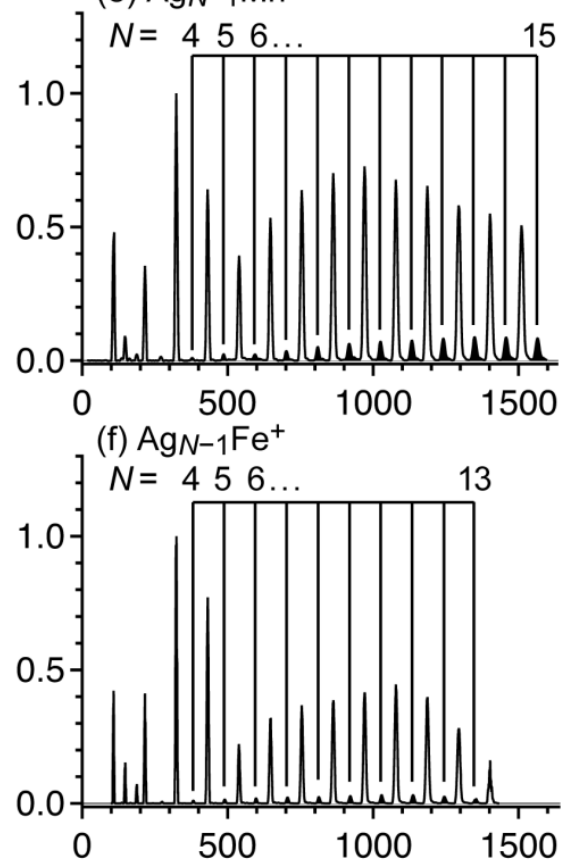

(g) $\mathrm{Ag}_{\mathrm{N}-1} \mathrm{Co}^{+}$

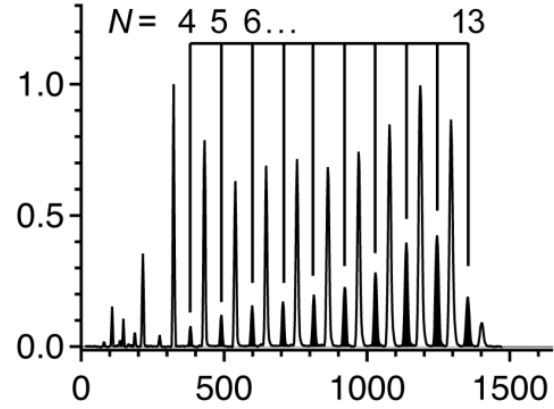

(h) $\mathrm{Ag}_{\mathrm{N}-1} \mathrm{Ni}^{+}$

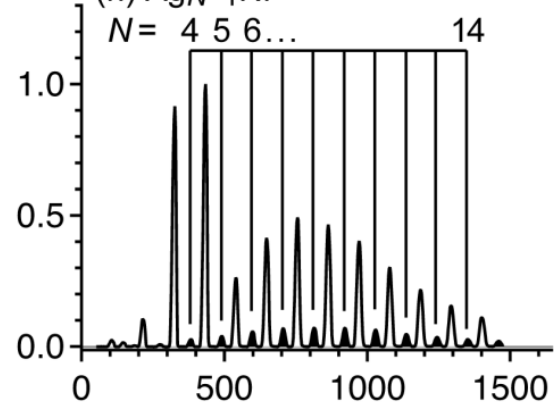

Mass / u

Figure S1. Typical mass spectra of cluster cations produced in a magnetron sputter ion source by simultaneous sputtering of silver with (a) scandium, (b) titanium, (c) vanadium, (d) chromium, (e) manganese, (f) iron, (g) cobalt, and (h) nickel. Singly doped silver clusters as well as pure silver clusters are observed. 


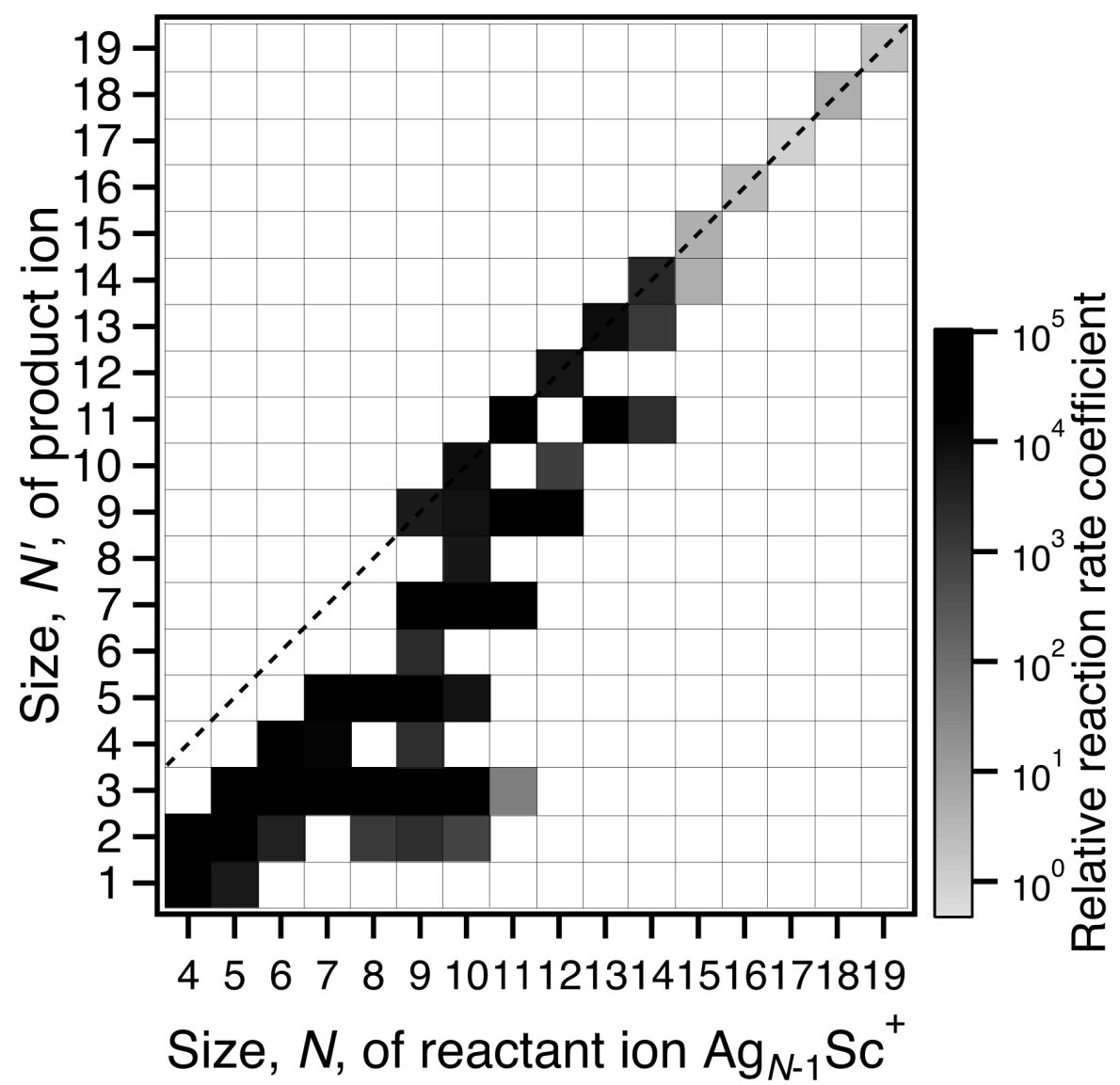

Figure S2. Partial reaction rate coefficients of $\mathrm{Ag}_{N-1} \mathrm{Sc}^{+}$shown in the same manner as Fig. 3. The rate coefficients show relative values with respect to that of $N=17$ producing $\mathrm{O}_{2}$ adducts. 


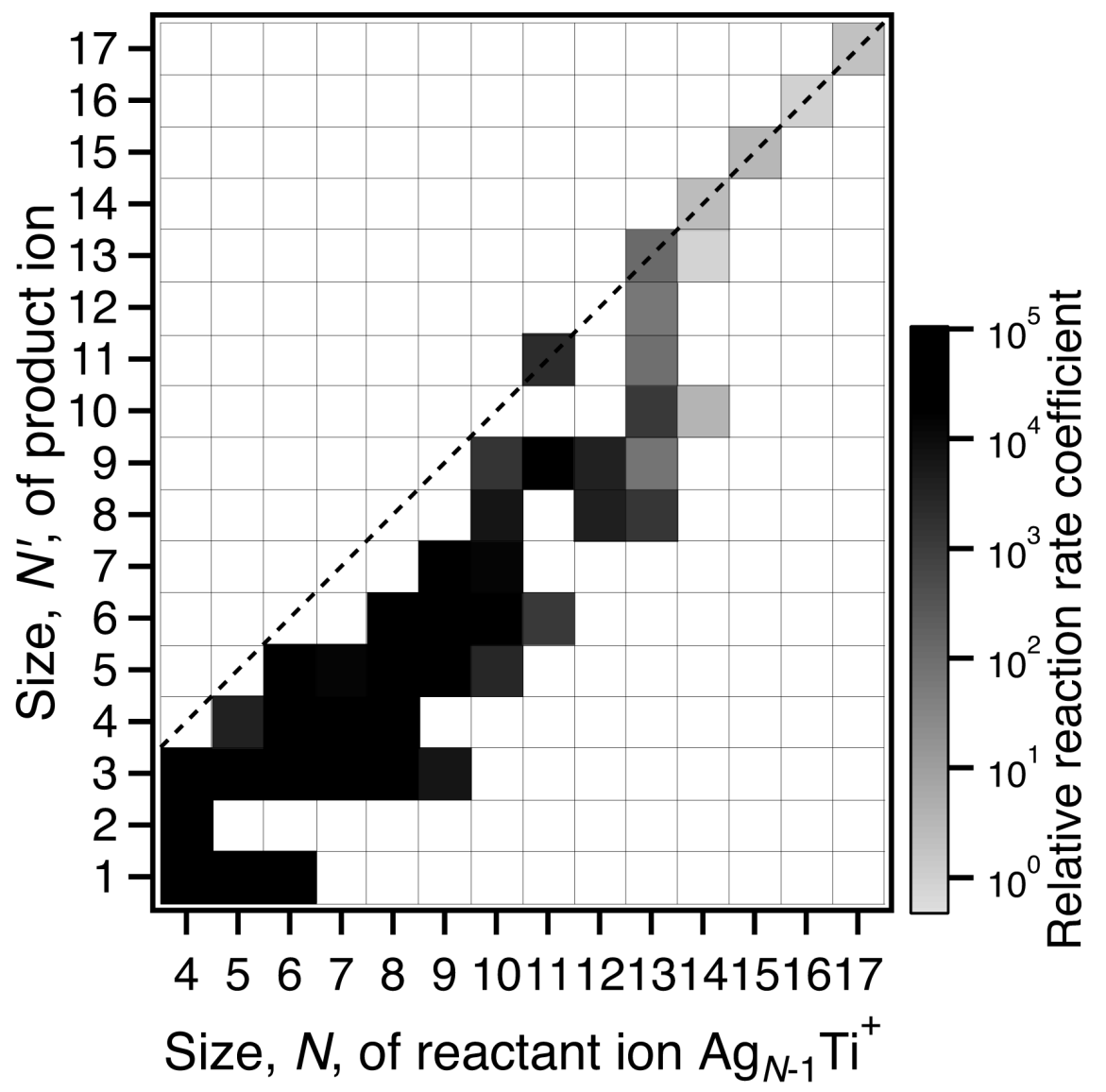

Figure S3. Partial reaction rate coefficients of $\mathrm{Ag}_{N-1} \mathrm{Ti}^{+}$shown in the same manner as Fig. 3. The rate coefficients show relative values with respect to that of $N=16$. 


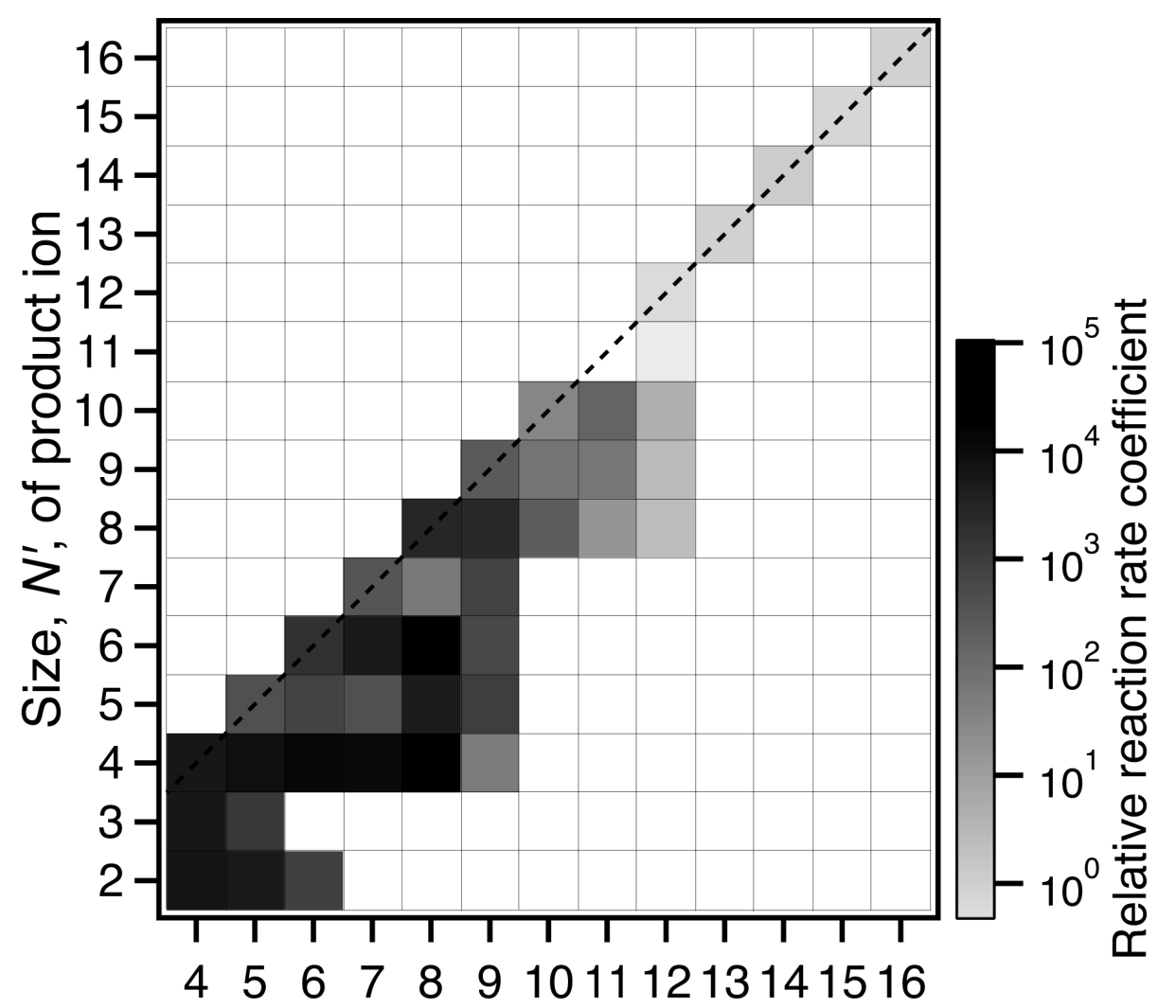

Size, $N$, of reactant ion $\mathrm{Ag}_{\mathrm{N}-1} \mathrm{~V}^{+}$

Figure S4. Partial reaction rate coefficients of $\mathrm{Ag}_{N-1} \mathrm{~V}^{+}$shown in the same manner as Fig.

3. The rate coefficients show relative values with respect to that of $N=13$. 


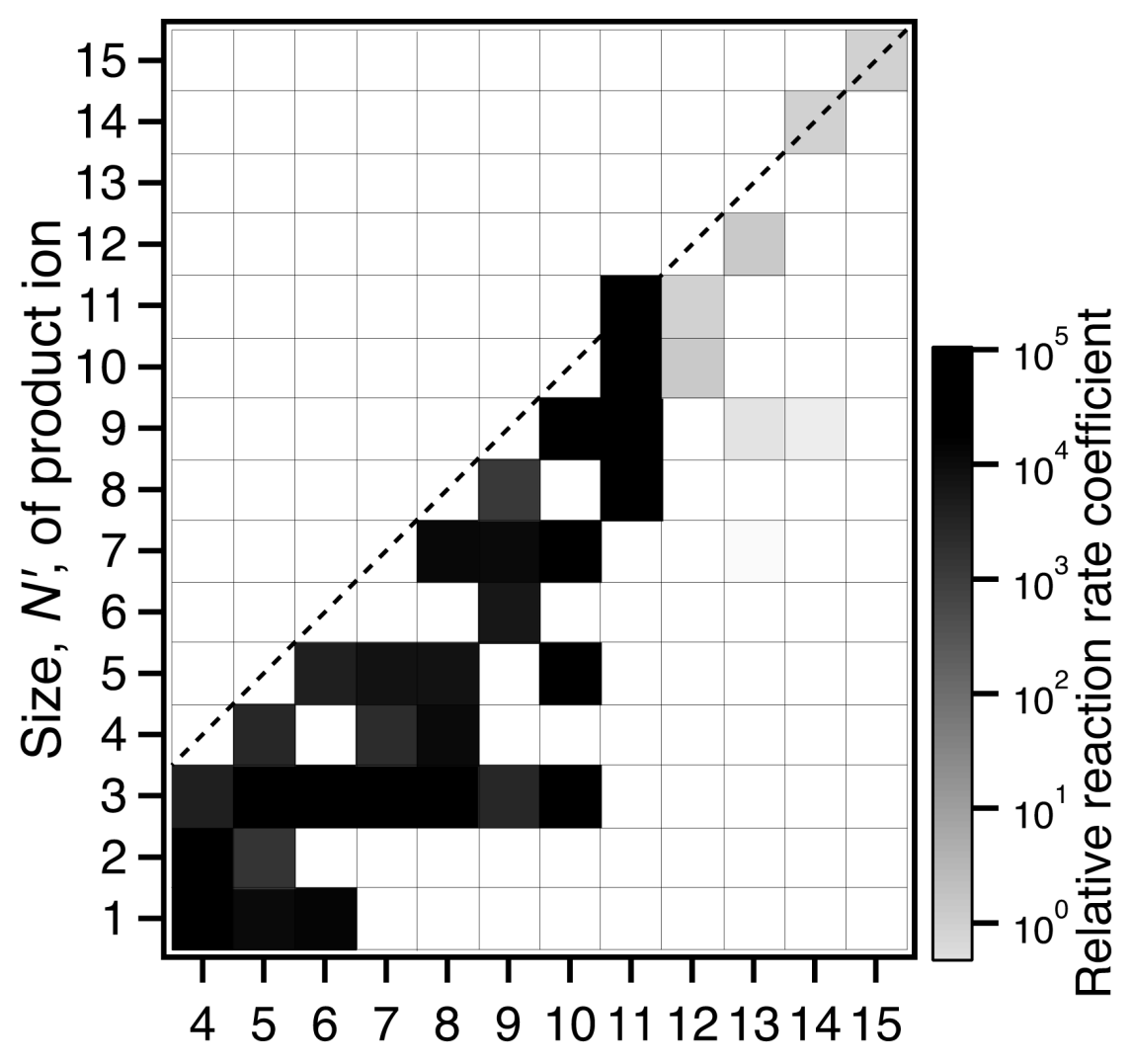

Size, $N$, of reactant ion $\mathrm{Ag}_{\mathrm{N}-1} \mathrm{Cr}^{+}$

Figure S5. Partial reaction rate coefficients of $\mathrm{Ag}_{N-1} \mathrm{Cr}^{+}$shown in the same manner as Fig. 3. The rate coefficients show relative values with respect to that of $N=14$. 


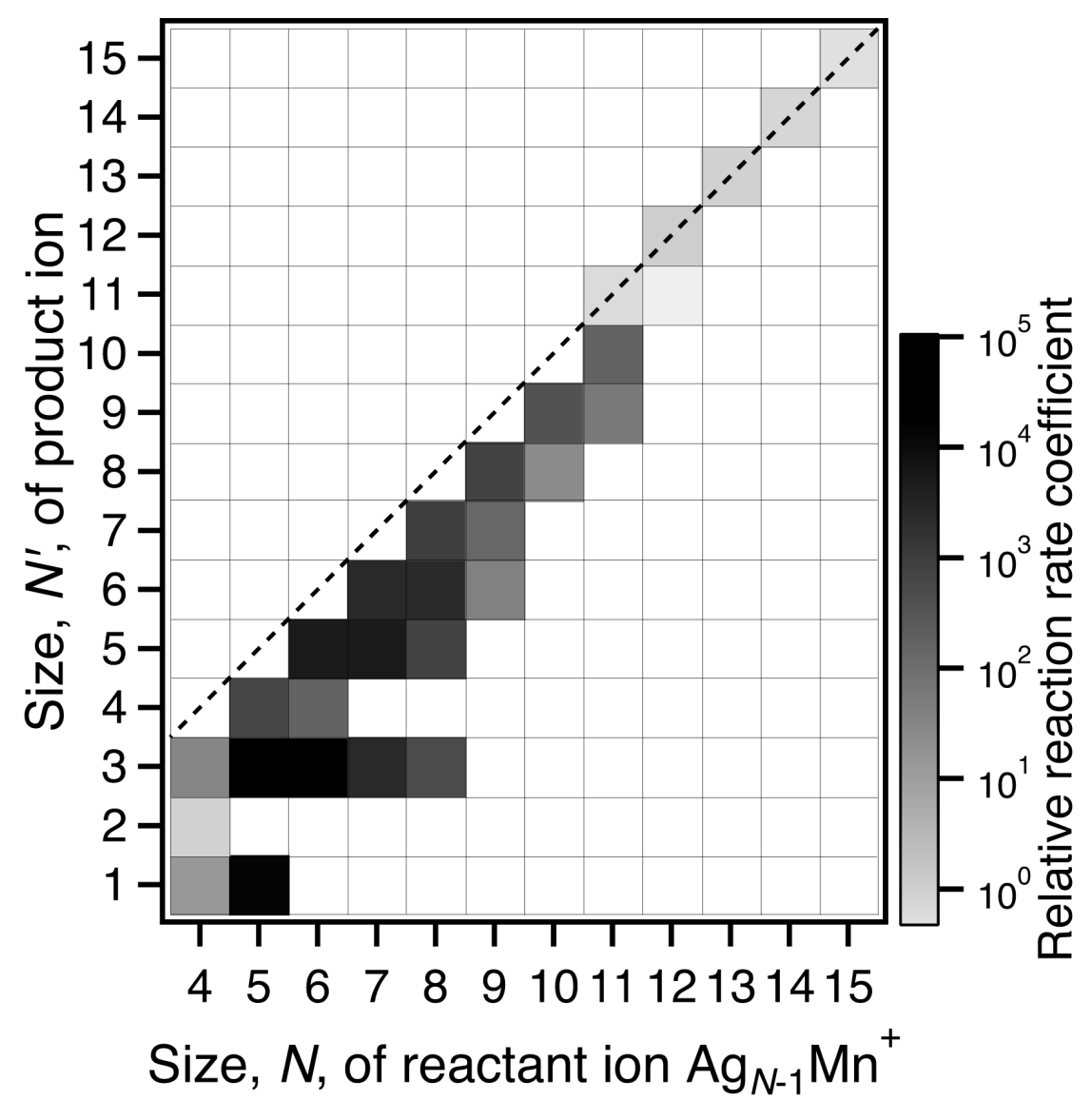

Figure S6. Partial reaction rate coefficients of $\mathrm{Ag}_{N-1} \mathrm{Mn}^{+}$shown in the same manner as Fig. 3. The rate coefficients show relative values with respect to that of $N=13$. 


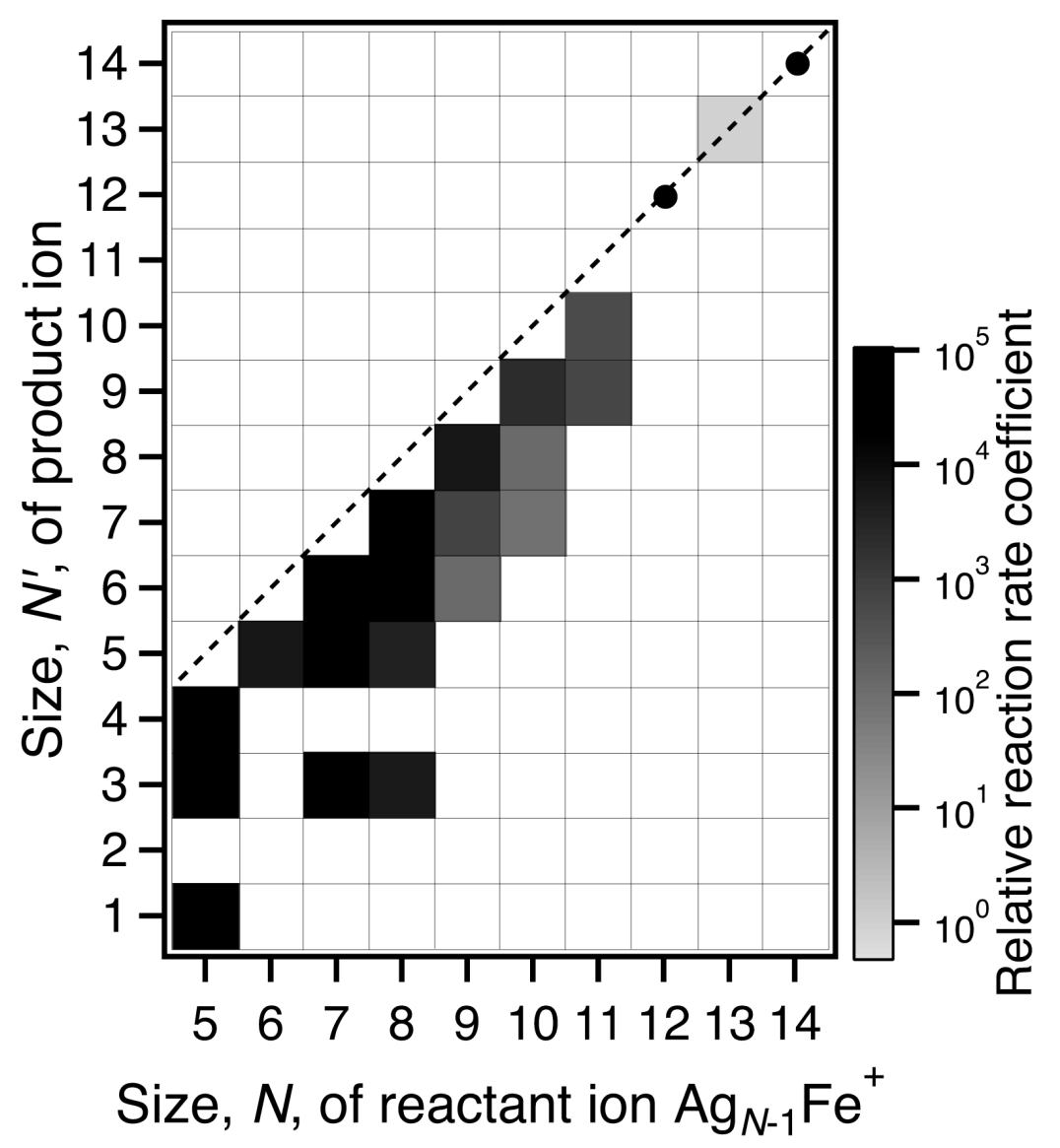

Figure S7. Partial reaction rate coefficients of $\mathrm{Ag}_{N-1} \mathrm{Fe}^{+}$shown in the same manner as Fig. 3. The rate coefficients show relative values with respect to that of $N=13$. The pixels marked with $\bullet$ indicate that no reaction products were observed for $\mathrm{Ag}_{12} \mathrm{Fe}^{+}$and $\mathrm{Ag}_{14} \mathrm{Fe}^{+}$. 


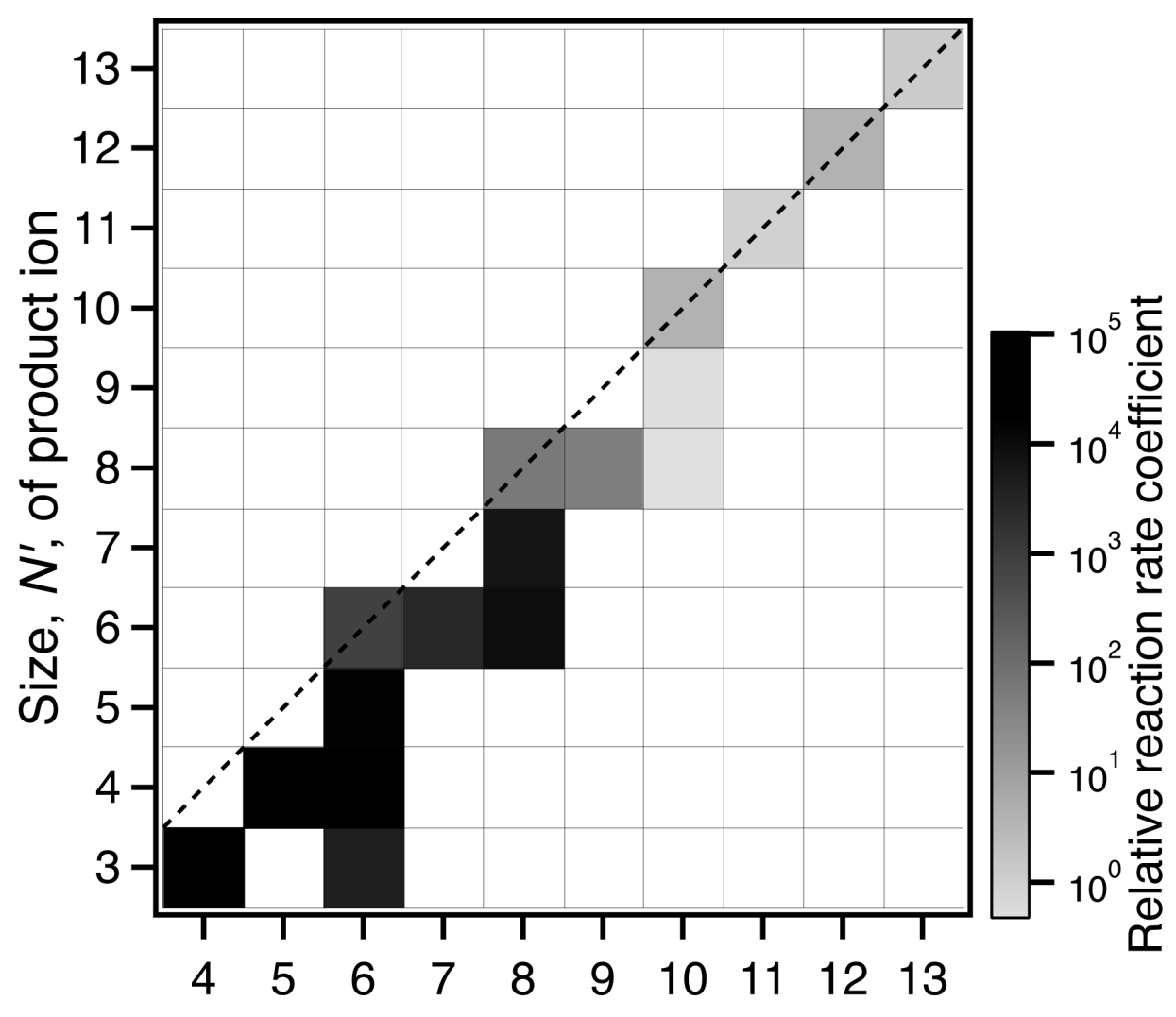

Size, $N$, of reactant ion $\mathrm{Ag}_{N-1} \mathrm{Co}^{+}$

Figure S8. Partial reaction rate coefficients of $\mathrm{Ag}_{N-1} \mathrm{Co}^{+}$shown in the same manner as Fig. 3. The rate coefficients show relative values with respect to that of $N=11$. 


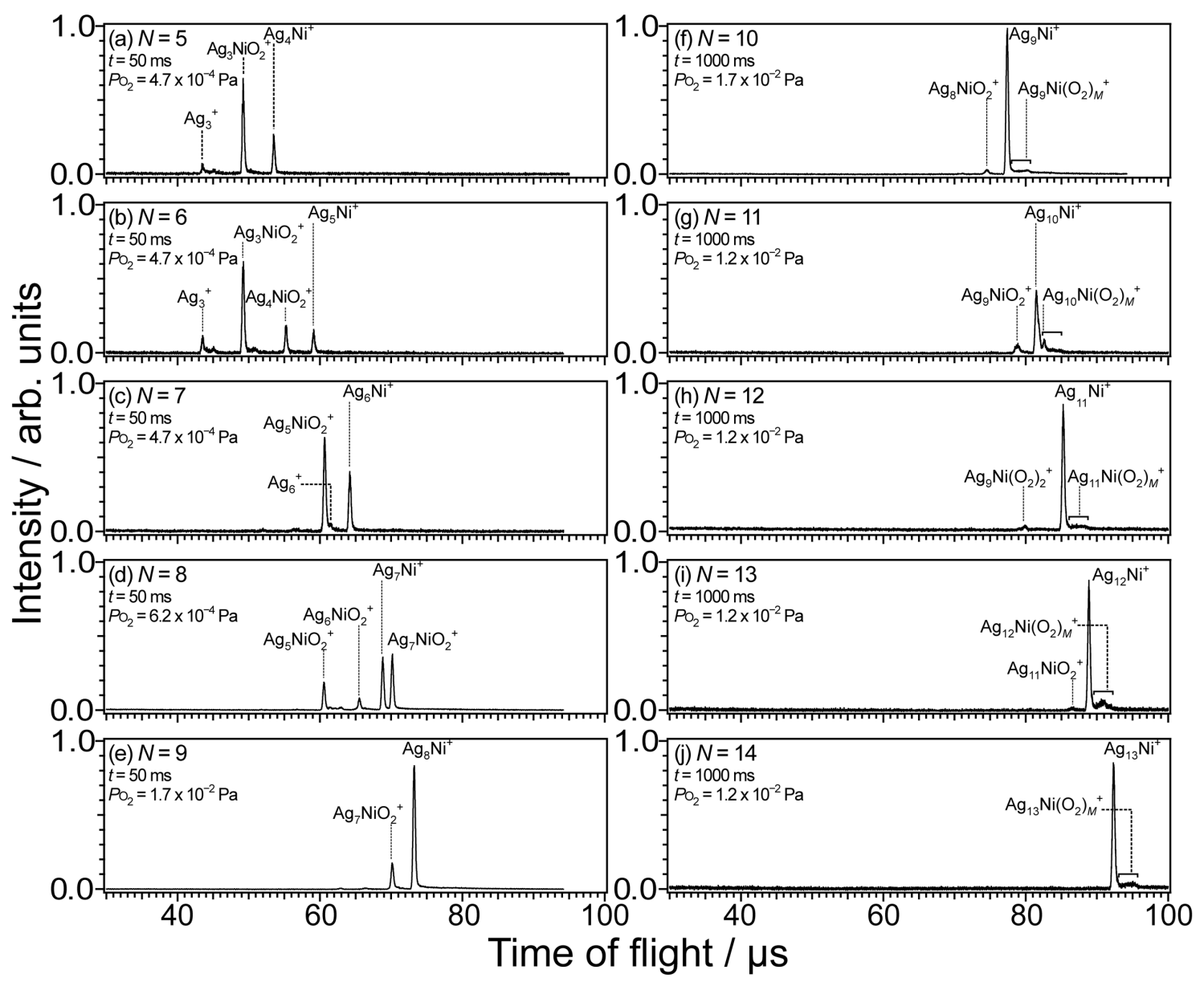

Figure S9. Time-of-flight mass spectra of product ions upon reaction of $\mathrm{Ag}_{N-1} \mathrm{Ni}^{+}$with $\mathrm{O}_{2}$. Reaction time $t$ and partial pressure $P_{\mathrm{O} 2}$ of $\mathrm{O}_{2}$ in the ion trap are indicated for each size. 

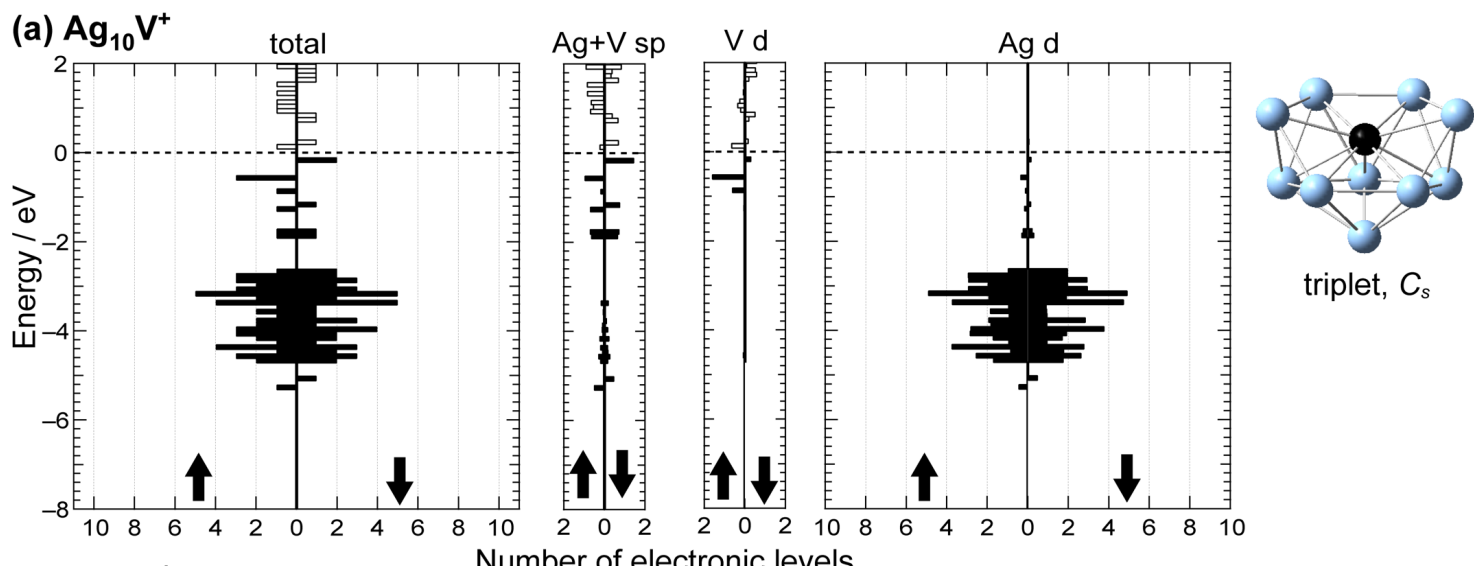

triplet, $C_{s}$

(b) $\mathrm{Ag}_{14} \mathrm{~V}^{+}$ Number of electronic levels
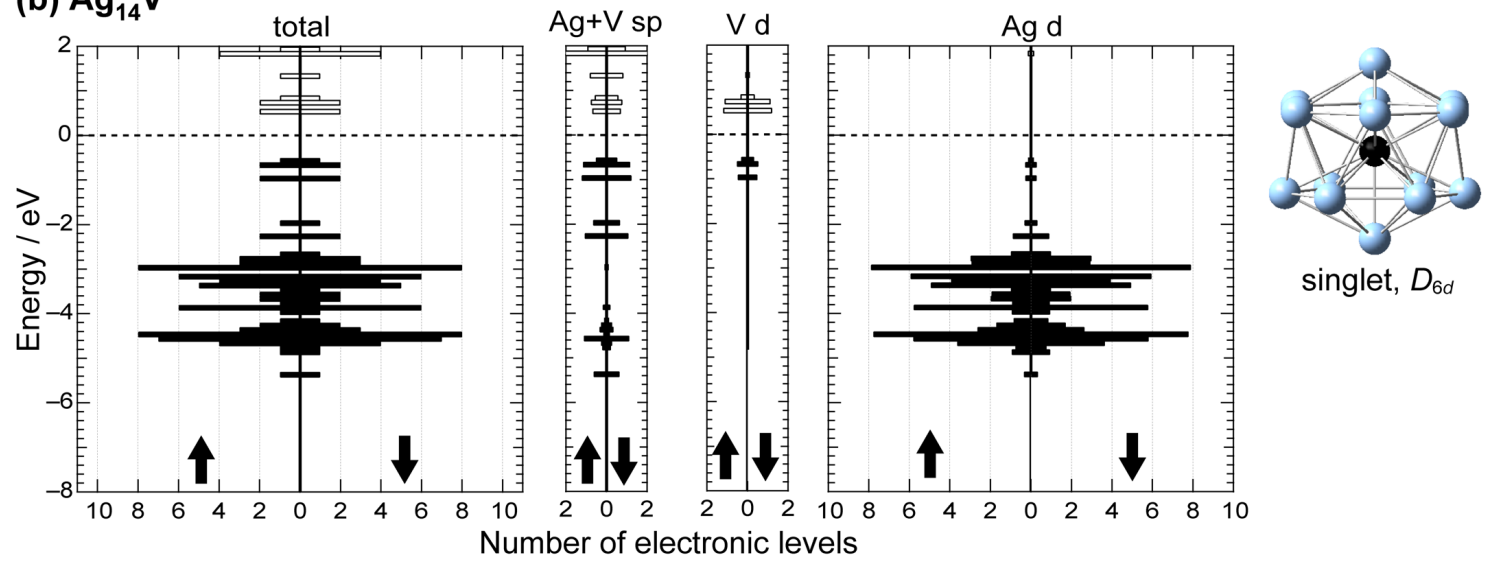

Figure S10. Electronic structures of (a) $\mathrm{Ag}_{10} \mathrm{~V}^{+}$and (b) $\mathrm{Ag}_{14} \mathrm{~V}^{+}$as well as their optimized structures obtained by DFT calculations. The BLYP functional is examined instead of B3LYP ${ }^{\star}$ employed in Fig. 5. The 6-31G(d,p) basis set is used for vanadium, while the def2-TZVPP basis set with def2-ECP is used for silver. 

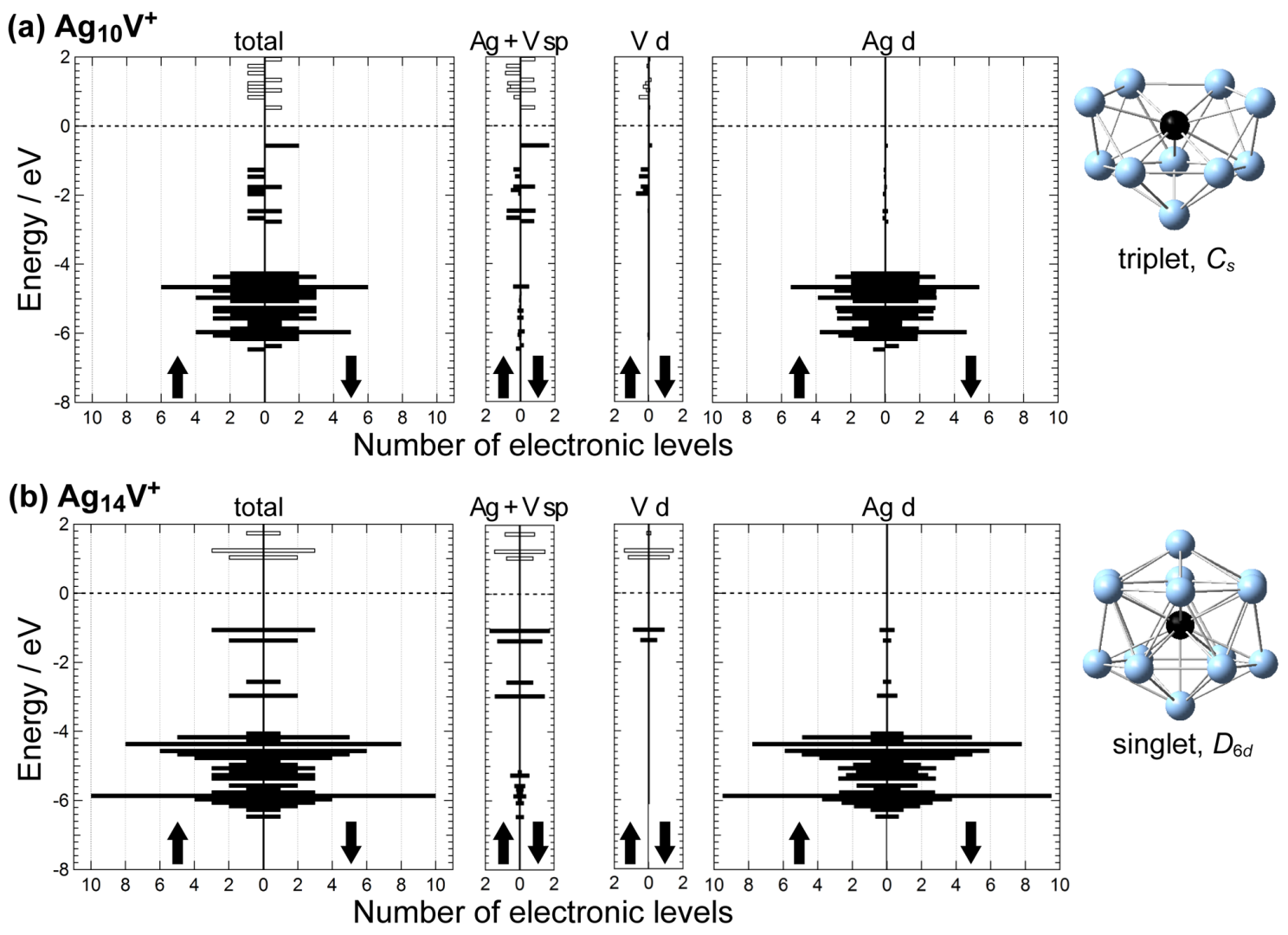

Figure S11. Electronic structures of (a) $\mathrm{Ag}_{10} \mathrm{~V}^{+}$and (b) $\mathrm{Ag}_{14} \mathrm{~V}^{+}$as well as their optimized structures obtained by DFT calculations. The LanL2DZ basis set with corresponding effective core potential is used for the silver atoms insterad of def2-TZVPP in Fig. 5. The $\mathrm{B} 3 \mathrm{LYP}^{\star}$ functional is employed. 


\section{$\mathrm{Ag}_{12} \mathrm{Mn}^{+}$}

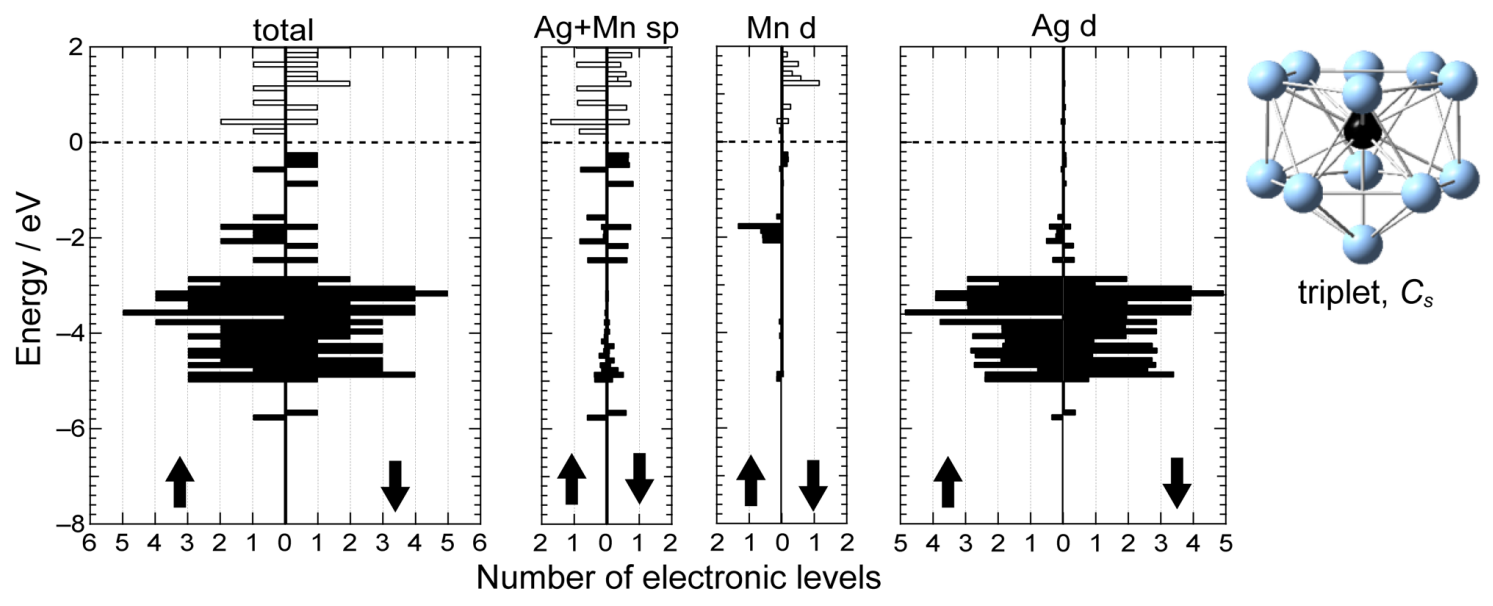

Figure S12. Electronic structure of $\mathrm{Ag}_{12} \mathrm{Mn}^{+}$and its optimized structure obtained by DFT calculation. The BLYP functional is examined instead of B3LYP ${ }^{\star}$ employed in Fig. 6. The 6-31G(d,p) basis set is used for manganese, while the def2-TZVPP basis set with def2-ECP is used for silver. 


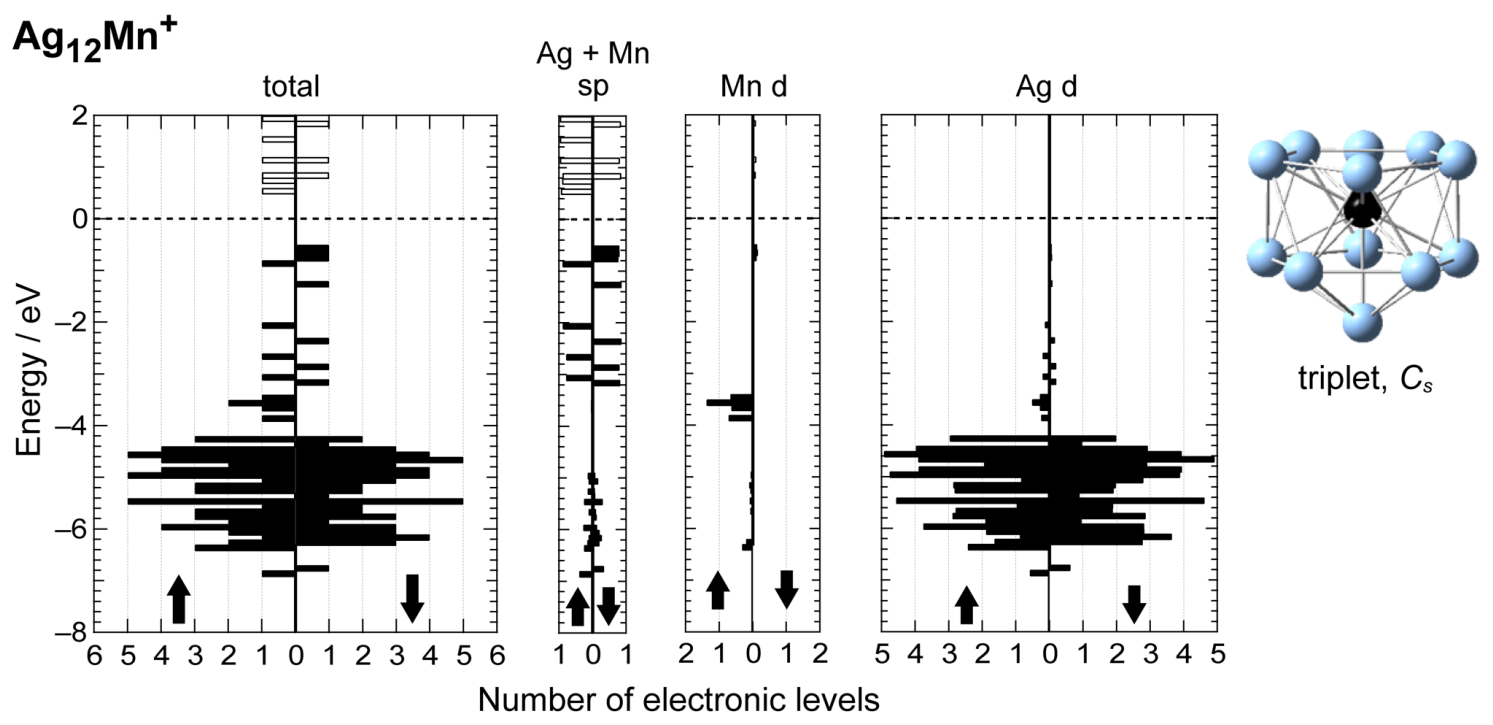

Figure S13. Electronic structure of $\mathrm{Ag}_{12} \mathrm{Mn}^{+}$and its optimized structure obtained by DFT calculation. The LanL2DZ basis set with corresponding effective core potential was used for the silver atoms insterad of def2-TZVPP in Fig. 6. The B3LYP^ functional is employed. 


\section{Complete author lists of refs. 22 and 35.}

(22) Frisch, M. J.; Trucks, G. W.; Schlegel, H. B.; Scuseria, G. E.; Robb, M. A.; Cheeseman, J. R.; Scalmani, G.; Barone, V.; Petersson, G. A.; Nakatsuji, H.; Li, X.; Caricato, M.; Marenich, A. V.; Bloino, J.; Janesko, B. G.; Gomperts, R.; Mennucci, B.; Hratchian, H. P.; Ortiz, J. V.; Izmaylov, A. F.; Sonnenberg, J. L.; Williams-Young, D.;

Ding, F.; Lipparini, F.; Egidi, F.; Goings, J.; Peng, B.; Petrone, A.; Henderson, T.; Ranasinghe, D.; Zakrzewski, V. G.; Gao, J.; Rega, N.; Zheng, G.; Liang, W.; Hada, M.; Ehara, M.; Toyota, K.; Fukuda, R.; Hasegawa, J.; Ishida, M.; Nakajima, T.; Honda, Y.; Kitao, O.; Nakai, H.; Vreven, T.; Throssell, K.; Montgomery, J. A., Jr.; Peralta, J. E.; Ogliaro, F.; Bearpark, M. J.; Heyd, J. J.; Brothers, E. N.; Kudin, K. N.; Staroverov, V. N.; Keith, T. A.; Kobayashi, R.; Normand, J.; Raghavachari, K.; Rendell, A. P.; Burant, J. C.; Iyengar, S. S.; Tomasi, J.; Cossi, M.; Millam, J. M.; Klene, M.; Adamo, C.; Cammi, R.; Ochterski, J. W.; Martin, R. L.; Morokuma, K.; Farkas, O.; Foresman, J. B.; Fox, D. J. Gaussian 16, revision A.03; Gaussian, Inc.: Wallingford, CT, 2016.

(35) Zamudio-Bayer, V.; Leppert, L.; Hirsch, K.; Langenberg, A.; Rittmann, J.; Kossick, M.; Vogel, M.; Richter, R.; Terasaki, A.; Möller, T.; von Issendorff, B.; Kümmel, S.; Lau, J. T. Coordination-Driven Magnetic-to-Nonmagnetic Transition in Manganese-Doped Silicon Clusters. Phys. Rev. B 2013, 88, 115425. 